\title{
Long-term facial changes and clinical correlations in patients with treated acromegaly: a cohort study
}

\section{Fengzhou Du' ${ }^{1}$, Qiao Chen' ${ }^{1}$ Xiaojun Wang ${ }^{1}$, Xiaopeng Guo², Zihao Wang ${ }^{2}$ Lu Gao², Xiao Long ${ }^{1}$ and Bing Xing ${ }^{2}$}

${ }^{1}$ Department of Plastic and Reconstructive Surgery and ${ }^{2}$ Department of Neurosurgery, Peking Union Medical College Hospital, Chinese Academy of Medical Sciences and Peking Union Medical College, Beijing, China
Correspondence should be addressed to X Long or B Xing Email pumclongxiao@126.com or xingb@pumch.cn

\begin{abstract}
Background: Facial abnormality is the most significant feature in acromegaly patients. However, it is unclear whether and how patient facial appearance improves after treatment. This study aimed to identify 3D facial changes in acromegaly patients after surgical treatment.

Methods: This study included 30 acromegaly patients who underwent resection of a pituitary GH adenoma. The location and extent of facial changes were identified by comparing baseline and 2-year follow-up 3D images of the face. Relationships between facial changes and GH and IGF-1 were evaluated with simple or multivariable linear regression models.

Results: Significant soft tissue improvements were observed in acromegaly patients with complete remission, especially in the nose and lip region. Significant reductions in nasal width $(3.46 \mathrm{~mm}, P<0.001)$, tip protrusion (1.18 $\mathrm{mm}, P=0.003)$, face curve length $(3.89 \mathrm{~mm}, P=0.004)$ and vermilion area $\left(1.42 \mathrm{~cm}^{3}, P=0.001\right)$ were observed at the 2-year follow-up. Further, changes in nasal width were associated with decreases in GH $(\beta=4.440, P=0.017)$, the GH nadir $(\beta=4.393, P=0.011)$ and IGF-1 ( $\beta=5.263, P=0.002)$. The associations were maintained after adjusting for confounders.

Conclusions: Acromegaly patients achieved considerable facial improvements after surgical treatment. The change in nose width was associated with GH and IGF-1 decrease. Better control of patient hormone levels after surgery improves patient facial recovery.
\end{abstract}

\section{Introduction}

Acromegaly is a chronic progressive endocrine disease with an occult onset. Approximately $95 \%$ of patients with acromegaly suffer from pituitary growth hormone (GH) adenomas (1). Long-term, excessive secretion of $\mathrm{GH}$ and IGF-1 leads to excessive hyperplasia of soft tissues, bones and cartilage throughout the body, causing changes in the face, hypertrophy of the hands and feet, thick skin, and enlarged internal organs, bones and joints. Facial abnormalities can cause patients to lack self-confidence and suffer from psychological trauma. Furthermore, abnormalities can cause abnormal maxillofacial function and significantly reduce patient quality of life (QoL) $(2,3)$.

Acromegaly can be effectively treated after diagnosis. Studies have shown that successful treatment may partially reverse thickening of articular cartilage and symptoms of sleep apnoea $(4,5)$. Understanding the quantitative changes in patient appearance after treatment are greatly significant for assessing disease prognosis and studying the pathophysiological characteristics of this disease. However, there are currently no prospective studies that

Published by Bioscientifica Ltd. 
quantitatively analyse facial changes in patients. Although patients are very concerned about facial changes after treatment, it is often difficult for doctors to accurately answer their questions.

Two-dimensional photos are often used for facial analysis of acromegaly patients. With the advancement of computer-aided diagnostic technology, artificial intelligence can improve the diagnostic efficiency of acromegaly by comparing differences in the face between normal people and acromegaly patients $(6,7)$. However, 2D photographs are difficult to quantitatively analyse, and a substantial amount of spatial information is lost. Recently, 3D stereo photography has gradually advanced and been applied in the medical field. This method can obtain detailed information, including length, depth, and volume, to comprehensively evaluate changes in the face or limbs (8). In our previous studies, 3D stereo photography was used to describe the face of acromegaly patients and quantitatively evaluate structural abnormalities such as nose width, length, and height; upper and lower lip thickness; nasolabial angle and nasofrontal angle (9).

The study utilized 3D imaging technology to collect 3D facial images of acromegaly patients before and after transnasal sphenoid pituitary adenoma resection. This study aimed to quantitatively analyse preoperative and postoperative facial changes in acromegaly patients and further explore relationships between these changes and GH and IGF-1 levels.

\section{Methods}

\section{Participants}

This is the first prospective cohort study focusing on postoperative facial changes in Chinese acromegaly patients (chictr.org, ChiCTR1900021359). This study prospectively enrolled acromegaly patients who were admitted to the Department of Neurosurgery, Peking Union Medical College Hospital (PUMCH), China from January 2017 to August 2017. The inclusion criteria were (i) patients of both sexes who were 18 years or older and had clinical manifestations of acromegaly (10); (ii) patients with IGF-1 levels greater than sex- and agematched normal levels (age-related reference range of IGF-1 levels at PUMCH were defined as follows: $18-20$ years, $127-584 \mathrm{ng} / \mathrm{mL}$; $21-25$ years, $116-358 \mathrm{ng} / \mathrm{mL}$; 26-30 years, $117-329 \mathrm{ng} / \mathrm{mL}$; 31-35 years, $115-307 \mathrm{ng} / \mathrm{mL}$; 36-40 years, $109-284 \mathrm{ng} / \mathrm{mL}$; $41-45$ years, $101-267$ $\mathrm{ng} / \mathrm{mL}$; $46-50$ years, $94-252 \mathrm{ng} / \mathrm{mL}$; $51-55$ years, $87-238$ $\mathrm{ng} / \mathrm{mL}$; $56-60$ years, $81-225 \mathrm{ng} / \mathrm{mL} ; 61-65$ years,
75-12 $\mathrm{ng} / \mathrm{mL}$ ) and GH nadir glucose inhibition test values $>0.4 \mathrm{ng} / \mathrm{mL}$ (1); (iii) patients who were newly diagnosed with the disease and received initial treatment (i.e. patients who had never received pituitary surgery, drug therapy, or radiation therapy before enrolment); (iv) patients with a pituitary adenoma based on enhanced MRI of the pituitary gland; (v) other pituitary-related hormones at normal reference levels. The exclusion criteria were (i) patients with elevated GH and IGF-1 levels caused by non-pituitary GH adenomas; (ii) patients who did not undergo surgery and (iii) patients who could not complete a facial evaluation after surgery.

This study was approved by the PUMCH Clinical Ethics Committee (approval ID: ZS-1324). Written informed consent was obtained from all participants. The researchers were authorized to use the participant photos and clinical data for the clinical study and for academic publication.

\section{Study design}

This was a prospective cohort study. We recorded clinical data from patients before surgery (age; sex; height weight; BMI; disease course; random GH, GH nadir, and IGF-1 levels). The random GH, GH nadir, and IGF-1 levels were measured 1-2 weeks preoperatively. All patients underwent 3D facial imaging before surgery. After excluding surgical contraindications, all of the patients underwent transsphenoidal pituitary tumour resection. If there were no surgical complications, patients were discharged 3 days after the operation. The patients were then followed up in the outpatient service. At the 2-year follow-up, facial 3D imaging was performed. If the patients did not meet the biochemical cure standard, including the presence of residual tumours or recurrent tumours, and had high GH and IGF-1 levels, we re-evaluated their conditions and prepared an optimized treatment. The complete remission criteria included normal postoperative IGF-1 levels and GH nadir values (based on a glucose tolerance test) below $0.4 \mathrm{ng} / \mathrm{mL}$ (11).

The disease course refers to the time period between acromegaly symptom presentation and diagnosis. The GH nadir value was obtained by an oral glucose tolerance test (OGTT). GH and IGF-1 were measured by chemiluminescence assays using an IMMULITE 2000 analyser (Siemens Healthcare Diagnostics) in a clinical laboratory at PUMCH. The assay procedure was described in a previously published study (12). The percent decrease in GH and IGF-1 was calculated as follows: percentage decrease $=\left(\right.$ value $_{\text {baseline }}-$ value $\left._{\text {follow-up }}\right) /$ value $_{\text {baseline }} \times 100 \%$. 


\section{Three-dimensional imaging and analysis}

A VECTRA H1-270 camera (Canfield Scientific, Parsippany, $\mathrm{NJ}$ ) was used for 3D imaging. Facial 3D imaging was performed by a plastic surgeon with more than 5 years of imaging experience. Each patient sat in front of a well-lit white background. Patients shaved their beard or moustache, removed their hats and glasses, their ears were visible, and patients with long hair used a headband to keep their hair out of their face. Each patient stood against the wall, relaxed their face, opened their eyes, closed their mouth, and looked ahead in a natural manner. Based on the instruction manual for the 3D camera, photos were taken that included antero-posterior and lateral $\left(45^{\circ}\right)$ views of both sides of the face.

Face measurements were performed using Mirror software (Canfield Scientific, Parsippany, NJ); each measurement was performed in duplicate, and the mean was calculated. According to a standard procedure reported by Farkas et al. (13), surface landmarks (Fig. 1) were first marked on each patient's face, including the glabella (g); nasion (n); pronasale (prn); subnasale (sn); alare (al); labiale superius (ls); labiale inferius (1i); stomion (sto); cheilion (ch); gnathion (gn); zygion (zy); endocanthion (en) and exocanthion (ex). The definition of each landmark is provided in Table 1.

The following measurements were performed:

1. Nose: nasal width (al-al), nasal length (n-prn), nasal curve length (n-prn-sn), tip protrusion (sn-prn),
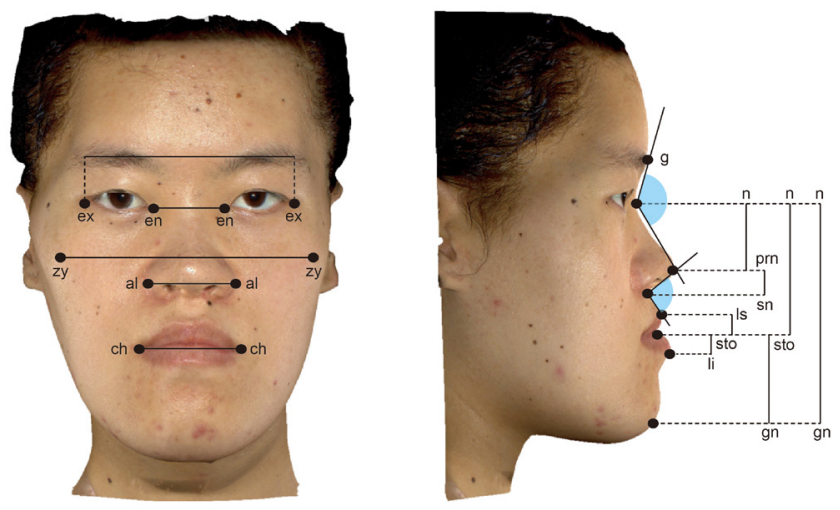

\section{Figure 1}

Landmarks used in face measurements. g, glabella; n, nasion; prn, pronasale; sn, subnasale; al, alare; Is, labiale superius; li, labiale inferius; sto, stomion; ch, cheilion; gn, gnathion; zy, zygion; en, endocanthion and ex, exocanthion. A full colour version of this figure is available at https://doi.org/10.1530/ EJE-20-0962. nasofrontal angle (g-n-prn) and columella-labial angle (prn-sn-ls).

2. Labio-oral region: mouth width (ch-ch), height of the upper lip vermilion (ls-sto), height of the lower lip vermilion (sto-li), and vermilion area.

3. Orbits: biocular diameter (ex-ex) and intercanthal distance (en-en).

4. Face: face length (n-gn), height of the upper face (n-sto), height of the lower face (sto-gn), face curve length (n-gn) and face width (zy-zy).

\section{Statistical analysis}

Descriptive results are expressed as the mean \pm standard deviation (S.D) for continuous variables or as the number of participants (percentages) for categorical variables. The facial parameters were tested for normality by ShapiroWilk test. The significance of facial changes between baseline and the 2-year follow-up were evaluated using paired $t$-tests. To investigate the relations between facial changes and GH, the GH nadir and IGF-1, simple and multivariable linear regression analyses were conducted. In model 1, simple linear regression analyses were performed without adjustments. In model 2, multivariable linear regression analyses were conducted after adjusting for sex, age and BMI. In model 3, adjustments were made for sex, age, BMI and disease course. Results are expressed as the regression coefficient $(\beta)$ with the $95 \% \mathrm{CI}$. $P$-values (two-tailed) $<0.05$ were considered statistically significant. All statistical analyses were performed using IBM SPSS statistics for Windows (version 21.0; IBM Corp).

\section{Results}

\section{Participant characteristics}

Patients were carefully screened for the inclusion and exclusion criteria. A total of 53 acromegaly patients were included in the study. The patients underwent 3D facial appearance evaluations and random GH, GH nadir, and IGF-1 tests before surgery. Among these patients, 23 were unable to complete the 2-year follow-up and were excluded from the study. Finally, data from 30 patients were available for analysis.

The clinical features of patients are summarized in Table 2 . The mean age of these patients was 41.3 years, and $1 / 3$ of patients were women. The mean BMI was $25.94 \mathrm{~kg} / \mathrm{m}^{2}$, and the mean disease course was 69.77 months. According to the tumour diameter, the patients 
Table 1 Analysed anthropometric landmarks.

\begin{tabular}{lll}
\cline { 1 - 1 } Landmark & Abbreviation \\
\cline { 1 - 1 } glabella & $\mathrm{g}$ \\
endocanthion & en \\
exocanthion & ex \\
nasion & $\mathrm{n}$ \\
pronasale & prn \\
subnasale & sn \\
alare & al \\
labiale superius & Is \\
labiale inferius & li \\
stomion & sto \\
cheilion & ch \\
gnathion & gn \\
zygion & zy \\
\end{tabular}

Definition
The most prominent midline point between the eyebrows
The point at the inner commissure of the eye fissure
The point at the outer commissure of the eye fissure
The point in the midline of both the nasal root and the nasofrontal suture
The most anterior midpoint of the nasal tip
The midpoint on the nasolabial soft tissue contour between the columella crest and the upper lip
The most lateral point on each alar contour
The midpoint of the upper vermilion line
The midpoint of the lower vermilion line
The imaginary point at the crossing of the vertical facial midline and the horizontal labial fissure
between gently closed lips, with teeth shut in natural position
The point located at each labial commissure
The lowest median landmark on the lower border of the mandible
The most lateral point of each zygomatic arch

were divided into the micro-adenoma (less than $10 \mathrm{~mm}$ ), macro-adenoma (10 and $30 \mathrm{~mm}$ ), and giant adenoma (larger than $30 \mathrm{~mm}$ ). As a result, 5 patients had microadenoma, 22 patients had macro-adenoma, and 3 patients had giant adenoma. The baseline GH level was $22.79 \mathrm{ng} /$ $\mathrm{mL}$ (s.D.=25.25), the $\mathrm{GH}$ nadir level was $15.18 \mathrm{ng} / \mathrm{mL}$ (s.D. = 18.55), and the mean IGF-1 level was $854.07 \mathrm{ng} / \mathrm{mL}$ (s.D. $=264.88$ ). At the 2-year follow-up, the mean GH level was $2.61 \mathrm{ng} / \mathrm{mL}$ (s.D. = 4.01), the mean GH nadir level was $1.29 \mathrm{ng} / \mathrm{mL}$ (s.D.=2.63), and the mean IGF-1 level was $360.70 \mathrm{ng} / \mathrm{mL}$ (s.D.=243.08). According to the criteria for complete remission, 12 patients had not achieved complete remission 2 years after surgery, while 18 patients

Table 2 Clinical characteristics of the study participants.

\begin{tabular}{|c|c|}
\hline & Mean (S.D) or $\boldsymbol{n}(\%)$ \\
\hline \multicolumn{2}{|l|}{ Gender } \\
\hline Male & $20(66.7 \%)$ \\
\hline Female & $10(33.3 \%)$ \\
\hline Age (years) & $41.30(10.41)$ \\
\hline Height (cm) & $171.47(7.39)$ \\
\hline Weight (kg) & $76.81(14.14)$ \\
\hline $\mathrm{BMI}\left(\mathrm{kg} / \mathrm{m}^{2}\right)$ & $25.94(3.25)$ \\
\hline Disease duration (months) & $69.77(58.62)$ \\
\hline \multicolumn{2}{|l|}{ Adenoma size } \\
\hline Micro-adenoma (<10 mm) & $5(16.7 \%)$ \\
\hline Macro-adenoma (10-30 mm) & $22(73.3 \%)$ \\
\hline Giant adenoma (> $30 \mathrm{~mm})$ & $3(10.0 \%)$ \\
\hline \multicolumn{2}{|l|}{$\mathrm{GH}(\mathrm{ng} / \mathrm{mL})$} \\
\hline Baseline & $22.79(25.25)$ \\
\hline 2-year follow-up & $2.61(4.01)$ \\
\hline \multicolumn{2}{|l|}{$\mathrm{GH}$ nadir $(\mathrm{ng} / \mathrm{mL})$} \\
\hline Baseline & $15.18(18.55)$ \\
\hline 2-year follow-up & $1.29(2.63)$ \\
\hline \multicolumn{2}{|l|}{ IGF-1 (ng/mL) } \\
\hline Baseline & $854.07(264.88)$ \\
\hline 2-year follow-up & $360.70(243.08)$ \\
\hline
\end{tabular}

GH, growth hormone; IGF-1, insulin-like growth factor 1 . achieved complete remission. The characteristics of the nose, labio-oral region, orbits and face of the 30 patients at baseline and the 2-year follow-up are described in Supplementary Table 1 (see section on supplementary materials given at the end of this article).

\section{Identification of 3D facial changes}

We compared 3D changes in patient facial appearance at baseline and the 2-year follow-up. All of the facial parameters in this study were continuous data, and the difference values were normally distributed. The heat map shows that significant facial improvement occurred in the nose and lip region. The overlay view clearly shows the restoration of side contours and shrinkage of the alae nasi. Typical cases are presented in Figs 2 and 3.

According to the remission criteria, patients were divided into an incomplete remission group and a complete remission group. Further quantitative analysis was performed to examine the facial, orbital, nasal and labio-oral areas in both groups (Tables 3 and 4).

\section{Nose parameters}

In the complete remission group, significant improvements in all nose parameters except nasal length were observed at the 2-year follow-up. There was a significant decrease in nasal width $(3.46 \mathrm{~mm}, P<0.001)$, nasal curve length (1.86 $\mathrm{mm}, P=0.002)$ and a reduction in tip protrusion (1.18 mm, $P=0.003)$. The nasofrontal angle $\left(3.23^{\circ}\right.$, $P=0.002)$ and columella-labial angle $\left(2.71^{\circ}, P=0.044\right)$ increased, making the face flatter. In the incomplete remission group, nasal width also decreased significantly ( $2.06 \mathrm{~mm}, P=0.002)$, although other parameters were not significantly different.

https://eje.bioscientifica.com 
A

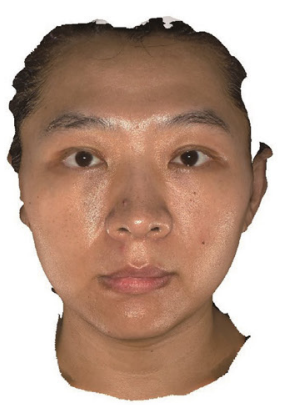

Pre

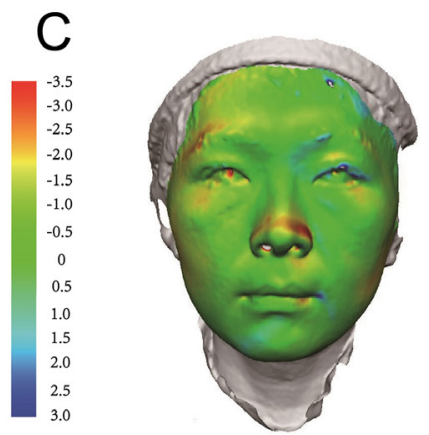

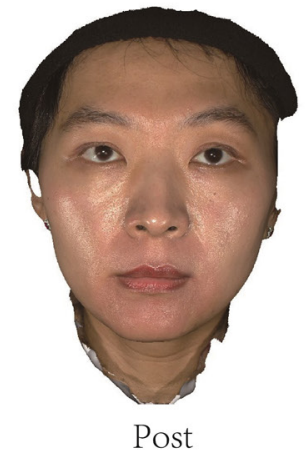

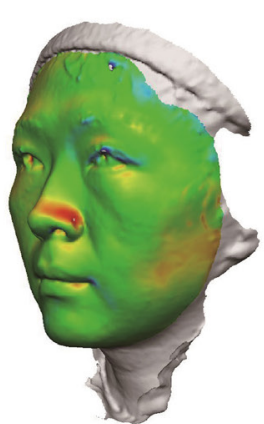

B

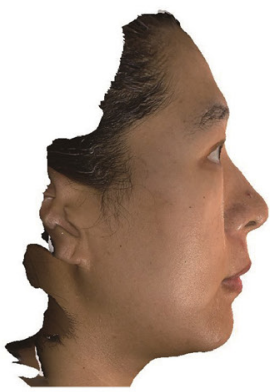

Pre

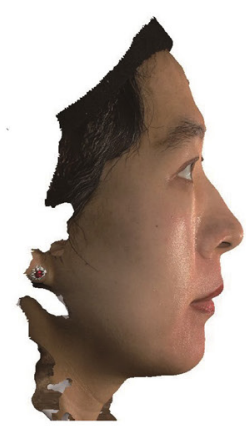

Post
D
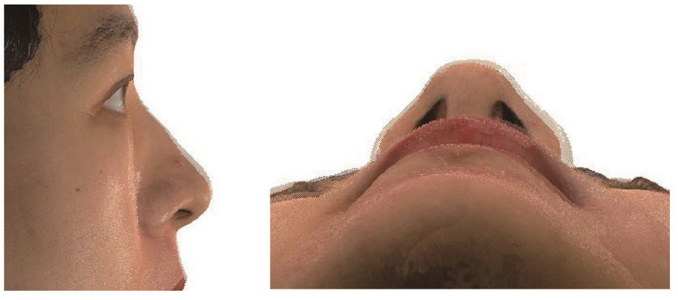

\section{Figure 2}

Typical case 1. A 34-year-old female acromegaly patient had random GH, GH nadir and IGF-1 levels of $25.6,17$ and 605 ng/mL, respectively, before surgery and underwent transsphenoidal pituitary tumour resection. Two years after surgery, her random $\mathrm{GH}$, GH nadir and IGF-1 levels decreased to $2.0,0.37$, and $206 \mathrm{ng} / \mathrm{mL}$, respectively. Panels A and B show 3D frontal and lateral images of her face before and 2 years after surgery, respectively. Panel $C$ shows the location and extent of facial changes with a heat map (green indicates that the difference is close to zero, and red indicates a decrease). Panel D shows significant improvements in lateral face contour and alae nasi in the overlay view. A full colour version of this figure is available at https://doi.org/10.1530/ EJE-20-0962.

\section{Labio-oral parameters}

All labio-oral parameters, including mouth width (0.96 mm, $P=0.034)$, height of the upper lip vermilion (0.46 mm, $P=0.031)$, height of the lower lip vermilion (1.26 mm, $P=0.001)$ and vermilion area $\left(1.42 \mathrm{~cm}^{3}\right.$, $P=0.001$ ), significantly decreased at the 2-year follow-up in the complete remission group. In the incomplete remission group, only the height of the lower lip vermilion $(1.18 \mathrm{~mm}, P=0.001)$ and vermilion area $\left(0.60 \mathrm{~cm}^{3}, P=0.034\right)$ significantly decreased.

\section{Orbit parameters}

Biocular diameters significantly decreased in both the complete remission group (1.52 $\mathrm{mm}, P=0.003)$ and the incomplete remission group $(1.81 \mathrm{~mm}, P=0.046)$. Intercanthal distances did not significantly change in either group.

\section{Face parameters}

In the complete remission group, face length $(1.60$ $\mathrm{mm}, P=0.023)$, height of the lower face $(1.68 \mathrm{~mm}$, $P=0.023)$, and face curve length $(3.89 \mathrm{~mm}, P=0.004)$ were significantly reduced at the follow- up compared with before surgery. In the incomplete remission group, only face curve length significantly changed (3.15 mm, $P=0.009$ ). The height of the upper face and face width at baseline and the 2-year follow-up in either group.

\section{Associations between GH, IGF-1 and facial improvements}

Table 5 shows the results of simple and multivariable linear regression analyses between GH or IGF-1 and changes in nasal width, vermilion area and face curve length. Although significant improvements were found 
A

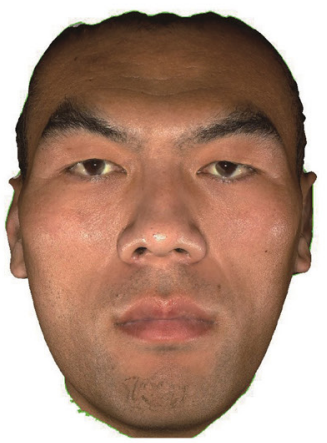

Pre

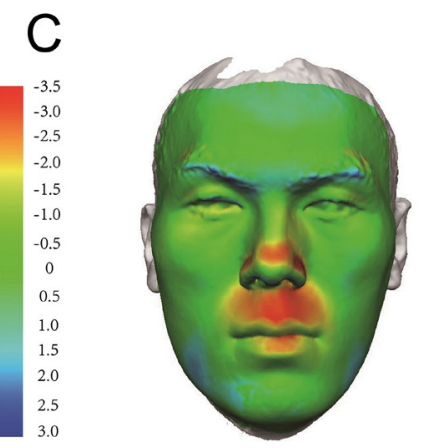

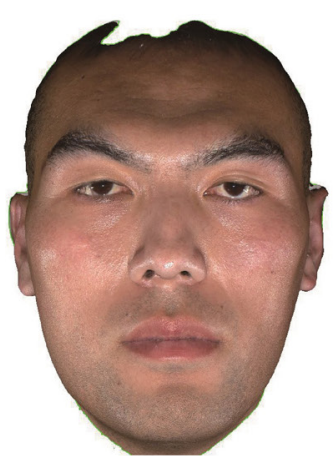

Post

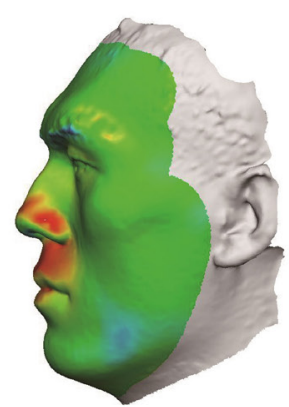

B

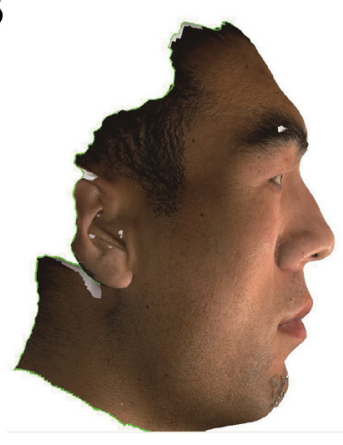

Pre

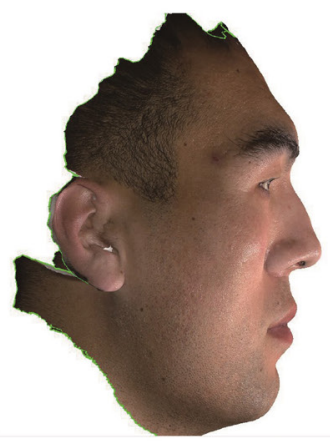

Post
D
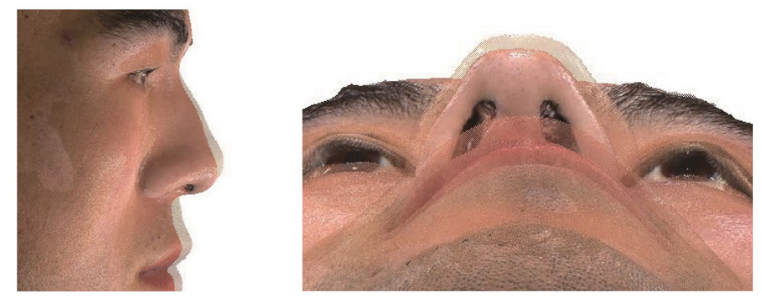

\section{Figure 3}

Typical case 2. A 27-year-old male acromegaly patient had random GH, GH nadir and IGF-1 levels of 34.6 , 31.5 and 1122 ng/mL, respectively, before surgery and underwent transsphenoidal pituitary tumour resection. Two years after surgery, his random $\mathrm{GH}$, GH nadir and IGF-1 levels decreased to 0.1, 0.05, and $208 \mathrm{ng} / \mathrm{mL}$, respectively. Panels A and B show 3D frontal and lateral images of his face before and 2 years after surgery, respectively. Panel $C$ shows the location and extent of facial changes with a heat map. Panel D shows significant improvements in lateral contour and alae nasi. A full colour version of this figure is available at https:// doi.org/10.1530/EJE-20-0962.

at the 2-year follow-up for other facial parameters, these parameters were not significantly associated with GH or IGF-1 (data not shown).

The change in nasal width was inversely associated with postoperative $\mathrm{GH}(\beta=-0.266, P=0.028)$ and $\mathrm{GH}$ nadir levels $(\beta=-0.378, P=0.028)$ after adjusting for sex, age and BMI or further adjusting for disease course. A significant correlation was observed between nasal width improvements and GH decreases $(\beta=4.440, P=0.017)$ as well as between nasal width improvements and GH nadir decreases $(\beta=4.393, P=0.011)$. These associations were maintained when adjusting for covariates in model 2 and model 3. Moreover, nasal width improvements were correlated with postoperative IGF-1 levels $(\beta=-0.004$, $P=0.019)$ and IGF-1 decreases $(\beta=5.263, P=0.002)$ in the unadjusted model. Notably, the results remained significant in the partially and completely adjusted models $(P<0.001)$.

A reduction in vermilion area was associated with $\mathrm{GH}$ decreases in both the unadjusted and adjusted models (model 1: $\beta=2.772, P=0.014 ;$ model 2: $\beta=2.705, P=0.024$; model 3: $\beta=2.414, P=0.041)$; $\mathrm{GH}$ nadir decreases after adjustment in model $3(\beta=2.307, P=0.037)$; IGF-1 decreases in the unadjusted $(\beta=2.114, P=0.048)$ and adjusted models.

A change in face curve length was significantly associated with GH decreases in the unadjusted simple linear regression analysis $(\beta=7.970, P=0.030)$ and fully adjusted multivariable linear regression analyses ( $\beta=7.510, P=0.033)$. No correlations were found between face curve length reductions and postoperative $\mathrm{GH}, \mathrm{GH}$ nadir or IGF-1 levels. 
Table 3 Quantitative facial changes of patients with complete remission at baseline and 2 years after surgical treatment. Results are expressed as mean \pm S.E., or as mean $(95 \% \mathrm{CI})$. Comparison between baseline and 2-year follow-up measurements was performed using paired $t$-test.

\begin{tabular}{|c|c|c|c|c|}
\hline & \multicolumn{4}{|c|}{ Complete remission $(n=18)$} \\
\hline & Baseline & Follow-up & Changes & $p$ \\
\hline $\mathrm{GH}(\mathrm{ng} / \mathrm{mL})$ & $20.82 \pm 23.46$ & $1.17 \pm 2.30$ & $-19.66(-31.49,-7.83)$ & 0.003 \\
\hline GH nadir (ng/mL) & $13.25 \pm 13.95$ & $0.21 \pm 0.10$ & $-13.04(-20.00,-6.09)$ & 0.001 \\
\hline IGF-1(ng/mL) & $869.72 \pm 258.48$ & $251.56 \pm 91.88$ & $-618.17(-750.43,-485.91)$ & $<0.001$ \\
\hline \multicolumn{5}{|l|}{ Nose parameters } \\
\hline Nasal width (mm) & $46.37 \pm 4.06$ & $42.91 \pm 4.17$ & $-3.46(-4.62,-2.30)$ & $<0.001$ \\
\hline Nasal length (mm) & $50.21 \pm 5.60$ & $49.72 \pm 5.22$ & $-0.49(-1.20,0.22)$ & 0.164 \\
\hline Nasal curve length (mm) & $73.20 \pm 7.41$ & $71.34 \pm 7.25$ & $-1.86(-2.97,-0.76)$ & 0.002 \\
\hline Nasal tip protrusion (mm) & $19.69 \pm 2.85$ & $18.51 \pm 3.04$ & $-1.18(-1.89,-0.48)$ & 0.003 \\
\hline NFA (degree) & $140.77 \pm 7.82$ & $144.00 \pm 8.87$ & $3.23(1.35,5.11)$ & 0.002 \\
\hline CLA (degree) & $103.92 \pm 14.81$ & $106.64 \pm 13.85$ & $2.71(0.09,5.34)$ & 0.044 \\
\hline \multicolumn{5}{|l|}{ Labio-oral parameters } \\
\hline Mouth width (mm) & $53.98 \pm 3.18$ & $53.02 \pm 3.56$ & $-0.96(-1.83,-0.08)$ & 0.034 \\
\hline Height of the upper lip vermilion (mm) & $11.58 \pm 1.58$ & $11.13 \pm 1.50$ & $-0.46(-0.86,-0.05)$ & 0.031 \\
\hline Height of the lower lip vermilion (mm) & $12.65 \pm 2.39$ & $11.38 \pm 2.68$ & $-1.26(-1.92,-0.62)$ & 0.001 \\
\hline Area of the vermilion $\left(\mathrm{cm}^{3}\right)$ & $12.80 \pm 2.43$ & $11.38 \pm 1.95$ & $-1.42(-2.17,-0.67)$ & 0.001 \\
\hline \multicolumn{5}{|l|}{ Orbits parameters } \\
\hline Biocular diameter (mm) & $100.19 \pm 4.94$ & $98.66 \pm 5.17$ & $-1.52(-2.45,-0.59)$ & 0.003 \\
\hline Intercanthal distance (mm) & $36.87 \pm 2.97$ & $36.68 \pm 3.23$ & $-0.19(-0.79,0.40)$ & 0.500 \\
\hline \multicolumn{5}{|l|}{ Face parameters } \\
\hline Face length (mm) & $132.29 \pm 8.68$ & $130.69 \pm 8.76$ & $-1.60(-2.94,-0.25)$ & 0.023 \\
\hline Height of the upper face $(\mathrm{mm})$ & $82.71 \pm 4.00$ & $81.78 \pm 3.86$ & $-0.93(-1.96,0.10)$ & 0.074 \\
\hline Height of the lower face (mm) & $52.84 \pm 5.75$ & $51.16 \pm 5.29$ & $-1.68(-3.09,-0.26)$ & 0.023 \\
\hline Face curve length (mm) & $166.29 \pm 14.48$ & $162.4 \pm 13.20$ & $-3.89(-6.32,-1.46)$ & 0.004 \\
\hline Face width (mm) & $131.62 \pm 12.34$ & $129.8 \pm 12.68$ & $-1.82(-3.88,0.24)$ & 0.079 \\
\hline
\end{tabular}

CLA, columella-labial angle; NFA, nasofrontal angle .

\section{Discussion}

Facial abnormality is the most significant feature in acromegaly patients, and acromegaly patients frequently want to know whether their facial appearance will improve after treatment. However, it was previously unclear whether facial appearance improves after treatment. This study is the first long-term cohort study to use 3D imaging to examine facial changes in acromegaly patients 2 years after surgery. Two-dimensional imaging was used in most previous studies that addressed facial changes in acromegaly patients $(14,15)$. However, the face is a complex 3D structure. Two-dimensional imaging cannot obtain all facial information; thus, changes in area, depth, and angle are often ignored $(16,17)$. After 3D image registration, the main areas of facial improvement can be directly visualized through overlay views and heat maps.

Previous cross-sectional studies indicated that there are significant differences between acromegaly patients after treatment and the normal population. In 2015, Wagenmakers et al. evaluated facial changes in 16 acromegaly patients in long-term remission and compared

those changes with facial features of 16 normal people. The results showed that compared with faces of individuals in the control group, faces of acromegaly patients were significantly wider, and in some acromegaly patients, typical skin soft tissue abnormalities were also observed (18). In 2016, a multi-centre study compared the hands of acromegaly patients who underwent surgery over 2 years ago with the hands of matched normal people. The results showed that even after a recovery period of at least 2 years, the finger length and width of acromegaly patients remained significantly different from those of individuals in the normal group (19). However, these studies could not answer questions about how patients changed after surgery. In addition, facial abnormalities between different patients have significant individual differences; therefore, the longitudinal comparison of individual images before and after treatment is more meaningful. This study was a prospective cohort study that addressed these important issues through a 2-year follow-up.

Our study, for the first time, quantified the reverse of soft tissue hypertrophy after elimination of the effects of high GH and IGF-1 levels via surgery. We found that 
Table 4 Quantitative facial changes of patients with incomplete remission at baseline and 2 years after surgical treatment. Results are expressed as mean \pm S.E., or as mean $(95 \% \mathrm{CI})$. Comparison between baseline and 2-year follow-up measurements was performed using paired $t$-test.

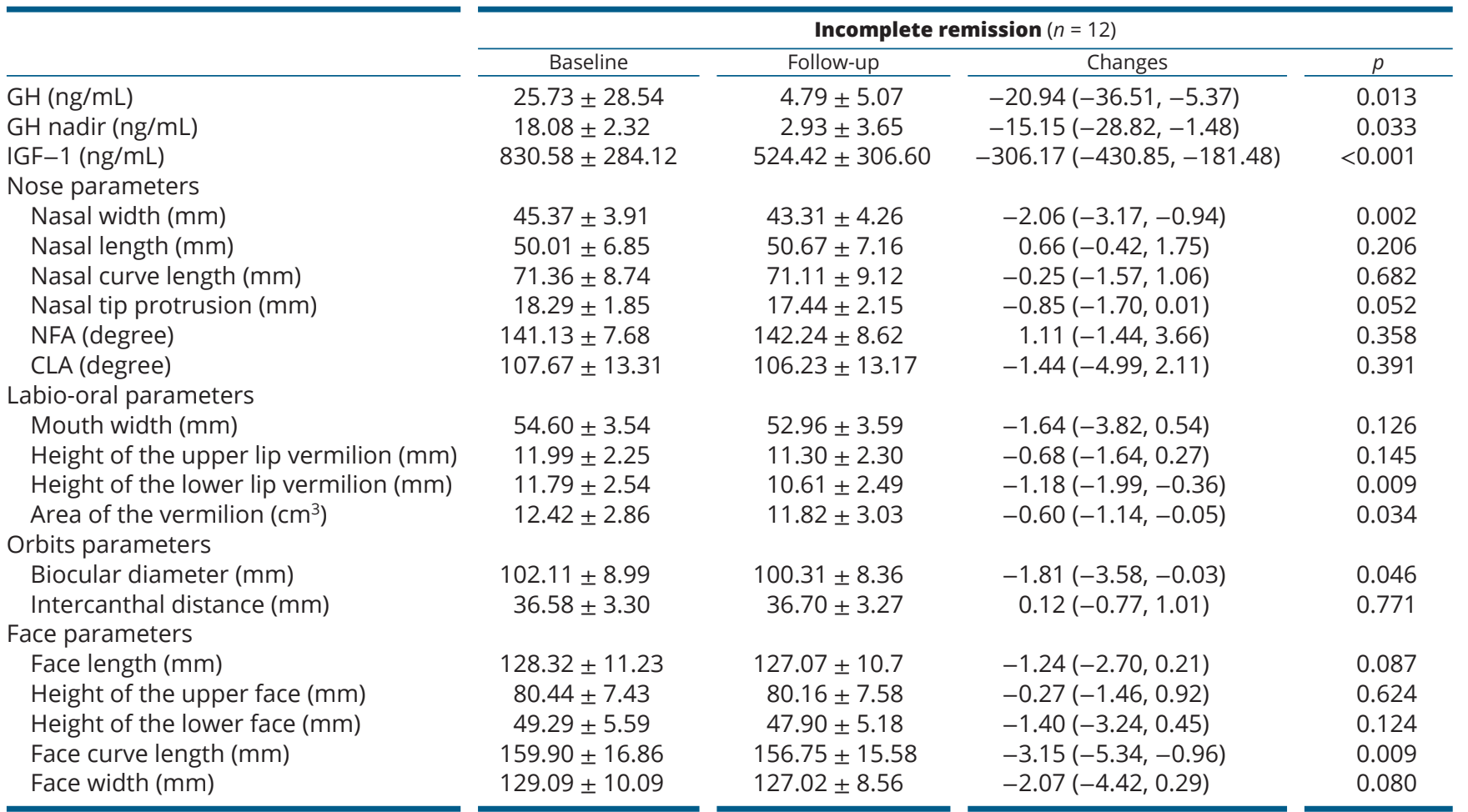

CLA, columella-labial angle;NFA, nasofrontal angle .

there were several important facial changes, mainly in the nose and lip region, in the complete remission group at the 2-year follow-up. Interestingly, our previous 3D study revealed that there are significantly abnormal areas of soft tissue in the lips and nose of acromegaly patients (9). In the present study, the patients with complete remission showed significantly reduced nasal width and tip protrusion and increased nasofrontal and columellalabial angles. The patients' lips also significantly changed after treatment; patients with complete remission exhibited reduced mouth width, thinner upper and lower lips and smaller vermilion areas. Most of these changes were in soft tissue rather than skeletal structure. These results are consistent with the cephalometric assessment reported by Dostalova et al. Their study found that there was no significant difference in bone parameters between a treated group and an untreated group (14).

Nose length (g-prn) is the only nasal parameter that did not significantly change because it is mainly determined by the nasal bone and septal cartilage. Similarly, face width (zy-zy), calculated by the distance between the bilateral zygomatic processes, did not significantly change. In the orbital area, the biocular diameter (ex-ex) decreased, while the intercanthal distance (en-en) did not significantly change. This may be due to the fact that the lateral canthal tendon (LCT) is more likely to deform horizontally (20). In the lower face, although the chin is supported by the mental protuberance of the mandible, the skin overlying the chin is thick and measures between 2.00 and $2.50 \mathrm{~mm}$ in most adults (21). Moreover, there are dense s.c. fat pads and musculature over the bony structure (22). As a result, the patients' pogonion (gn) moved up, causing the height of the lower face to decrease.

These 'minor' changes may be one of the keys to improving patient QoL. Many studies have shown that surgical treatments significantly improved the QoL of patients $(2,23,24)$. Furthermore, Sardella et al. showed that the improvements were mainly in their psychological and appearance domains rather than physical domains by using the acromegaly quality of life questionnaire (AcroQoL) (25). Although patient faces improved at the millimetre level in the current study, it had great aesthetic significance. The nose width (al-al) of patients with complete remission decreased by an average of $3.46 \mathrm{~mm}$ 
Table 5 Relationships between GH or IGF-1 and facial changes.

\begin{tabular}{l}
\hline \\
\hline Postoperative GH \\
Nasal width \\
Vermilion area \\
Face curve length \\
GH decrease (\%) \\
Nasal width \\
Vermilion area \\
Face curve length \\
Postoperative GH nadir \\
Nasal width \\
Vermilion area \\
Face curve length \\
GH nadir decrease (\%) \\
Nasal width \\
Vermilion area \\
Face curve length \\
Postoperative IGF-1 \\
Nasal width \\
Vermilion area \\
Face curve length \\
IGF-1 decreased (\%) \\
Nasal width \\
Vermilion area \\
Face curve length \\
\end{tabular}

\begin{tabular}{cc}
\hline \multicolumn{2}{c}{ Model 1 } \\
\hline$\beta(95 \% \mathrm{Cl})$ & $P$-value
\end{tabular}

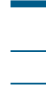

$\begin{array}{ll}-0.126(0.332,0.081) & 0.223 \\ -0.032(-0.160,0.096) & 0.612 \\ -0.194(-0.603,0.215) & 0.340\end{array}$

$-0.194(-0.603,0.215)$

$4.440(0.864,8.031)$

$2.772(0.611,4.934)$

$7.970(0.821,15.128)$

\subsection{7}

0.014

0.030

$-0.213(-0.527,0.101)$

$-0.026(-0.223,0.171)$

$-0.009(-0.646,0.627)$

0.175

0.787

0.976

$4.393(0.965,7.642)$

$2.034(-0.090,4.157)$

$1.555(-5.736,8.847)$

0.013

0.060

0.665

$-0.004(-0.007,0.001)$

$-0.001(-0.003,0.001)$

$0.003(-0.004,0.009)$

0.019

0.350

0.451

$5.263(2.172,8.354)$

$2.114(0.020,4.207)$

$-1.795(-9.021,5.430)$

0.002

0.048

0.615

\begin{tabular}{ccc}
\multicolumn{1}{c}{ Model 2} & \\
\hline \multicolumn{1}{c}{$\beta(95 \% \mathrm{Cl})$} & & $P$-value \\
$-0.266(-0.500,-0.032)$ & & 0.028 \\
$-0.038(-0.197, .0120)$ & & 0.622 \\
$-0.182(-0.644,0.281)$ & & 0.426 \\
& & \\
$4.680(0.994,8.381)$ & & 0.015 \\
$2.705(0.393,5.016)$ & & 0.024 \\
$6.779(-0.235,13.794)$ & & 0.058 \\
& \\
$-0.378(-0.718,-0.039)$ & & 0.030 \\
$-0.043(-0.273,0.186)$ & & 0.700 \\
$-0.072(-0.748,0.604)$ & & 0.827 \\
& & \\
$4.650(1.173,8.136)$ & & 0.011 \\
$2.205(-0.068,4.477)$ & & 0.057 \\
$3.646(-3.396,10.688)$ & & 0.296 \\
& \\
$-0.097(-0.009,-0.002)$ & & 0.003 \\
$-0.001(-0.004,0.001)$ & & 0.311 \\
$0.000(-0.008,0.007)$ & & 0.959 \\
& \\
$6.971(3.987,9.956)$ & $<0.001$ \\
$2.518(0.189,4.848)$ & 0.035 \\
$-0.105(-7.607,7.398)$ & 0.977 \\
\hline &
\end{tabular}

Model 1: simple linear regression analyses with no adjustment. Model 2: multivariable linear regression analyses adjusted for gender, age and BMI. Model 3: multivariable linear regression analyses adjusted for gender, age, BMI and disease course.

(2.30 to 4.62$)$, while the nasofrontal angle increased by an average of $3.23^{\circ}$ (1.35 to 5.11$)$, which is a considerable improvement even for rhinoplasty (26). In facial morphology, there are significant differences between male and female faces, but the range of the difference is also within a few millimetres. For example, a study of the Han Chinese faces showed that the sex difference in the lower vermilion height was only $0.34 \mathrm{~mm}$, which is one-third of the lower lip change in this study (27). These changes in facial features, which mainly involve soft tissue, have not been found in previous studies due to their small absolute values but were observed in our prospective study. These changes are important reasons for the improvements in patient mental health and QoL after surgery.

The degree of improvement from the treatment of acromegaly patients is significantly related to disease control. Patients with complete remission after treatment had more significant improvements than those without complete remission. However, multivariable linear regression analysis showed that not all improvements in the face index were linearly correlated with changes in GH or IGF-1. Among the parameters, the width of the nose has the strongest linear correlation with GH and IGF1. Regardless of whether simple or multivariable linear regression models were employed, the decreases in GH, the GH nadir and IGF-1 were significantly linearly related to the change in nose width. Although postoperative $\mathrm{GH}$ and the GH nadir were not significantly associated with nasal width in the simple linear regression model, significant negative associations were found when adjustments were made for possible confounders such as sex, age, BMI and disease course.

Facial abnormalities in acromegaly patients are caused by the long-term, chronic effects of GH and IGF-1 on bone, cartilage, and soft tissue (28). In 2018, Xie et al. found that decreased GH levels after surgery led to a redistribution of adipose tissue, with increased abdominal fat and reduced facial fat (29). As hormone levels decrease, cells of the cartilage and soft tissue divide faster than those of bone tissue $(30,31)$. These studies provide a theoretical basis for improvements in soft tissue in acromegaly patients, but the mechanism of facial improvements requires further study.

Our study has some limitations. This study examined patient facial changes 2 years after surgery and found that changes predominantly occurred in soft tissue. However, facial changes in acromegaly patients involve long-term processes, and processes related to bone tissue reconstruction may continue throughout life (32). Another limitation of our study is the small sample size. We did not have enough equipment or 3D images 
to examine more patients. Furthermore, only a few acromegaly patients underwent preoperative 3D imaging and long-term follow-up after surgery. In the future study, we would consider to involve more patients and to collect both short-term and long-term data in order to better understand the kinetics of facial changes after surgery.

In conclusion, this prospective study identified facial changes in acromegaly patients after treatment with 3D imaging. Patients who achieved complete remission showed considerable improvements in facial soft tissue 2 years after surgery, with significant changes in the nose and lips. This study found negative linear associations between postoperative $\mathrm{GH}$, the $\mathrm{GH}$ nadir and IGF-1 levels and nasal width reductions after adjusting for confounders. GH, the GH nadir and IGF-1 decreases after treatment were positively associated with nasal width and vermilion improvements. Thus, better control of patient hormone levels after surgery will improve patient facial recovery. Based on the current study, we suggested that facial measurement be used as a complementary assessment tool before treatment and in the follow-up clinic. Future large-scale and longer-term prospective studies may reveal patterns of change in facial soft tissue and bone tissue in acromegaly patients after treatment.

\section{Supplementary materials}

This is linked to the online version of the paper at https://doi.org/10.1530/ EJE-20-0962.

\section{Declaration of interest}

The authors declare that there is no conflict of interest that could be perceived as prejudicing the impartiality of this study.

\section{Funding}

This study was supported by the Medical and Health Innovation Project of the Chinese Academy of Medical Sciences (2018-I2M-Al-004), Key Projects of Strategic International Scientific and Technological Innovation Cooperation of the Chinese Ministry of Science and Technology (2020YFE0201600), and National Natural Science Foundation of China (81670444).

\section{Author contribution statement}

Fengzhou Du conducted the study and wrote the manuscript. Qiao Chen helped with 3D photography. Xiaojun Wang and Xiaopeng Guo assisted with the patient follow-up. Zihao Wang and Lu Gao helped to analyse data. Xiao Long and Bing Xing conceived and designed the project, oversaw the collection of results and data interpretation.

\section{References}

1 Katznelson L, Laws ER, Melmed S, Molitch ME, Murad MH, Utz A, Wass JAH \& Endocrine Society. Acromegaly: an Endocrine Society clinical practice guideline. Journal of Clinical Endocrinology and Metabolism 201499 3933-3951. (https://doi.org/10.1210/jc.2014-2700)

2 Matta MP, Couture E, Cazals L, Vezzosi D, Bennet A \& Caron P. Impaired quality of life of patients with acromegaly: control of GH/ IGF-I excess improves psychological subscale appearance. European Journal of Endocrinology 2008158 305-310. (https://doi.org/10.1530/ EJE-07-0697)

3 Vilar L, Vilar CF, Lyra R, Lyra R \& Naves LA. Acromegaly: clinical features at diagnosis. Pituitary 201720 22-32. (https://doi. org/10.1007/s11102-016-0772-8)

4 Ip MS, Tan KC, Peh WC \& Lam KS. Effect of Sandostatin LAR on sleep apnoea in acromegaly: correlation with computerized tomographic cephalometry and hormonal activity. Clinical Endocrinology 200155 477-483. (https://doi.org/10.1046/j.13652265.2001.01358.x)

5 Colao A, Marzullo P, Vallone G, Marino V, Annecchino M, Ferone D, De Brasi D, Scarpa R, Oriente P \& Lombardi G. Reversibility of joint thickening in acromegalic patients: an ultrasonography study. Journal of Clinical Endocrinology and Metabolism 199883 2121-2125. (https:// doi.org/10.1210/jcem.83.6.4865)

6 Wei R, Jiang C, Gao J, Xu P, Zhang D, Sun Z, Liu X, Deng K, Bao X, Sun $\mathrm{G}$ et al. Deep-learning approach to automatic identification of facial anomalies in endocrine disorders. Neuroendocrinology 2020110 328-337. (https://doi.org/10.1159/000502211)

7 Schneider HJ, Kosilek RP, Gunther M, Roemmler J, Stalla GK, Sievers C, Reincke M, Schopohl J \& Wurtz RP. A novel approach to the detection of acromegaly: accuracy of diagnosis by automatic face classification. Journal of Clinical Endocrinology and Metabolism 201196 2074-2080. (https://doi.org/10.1210/jc.2011-0237)

8 Heike CL, Upson K, Stuhaug E \& Weinberg SM. 3D digital stereophotogrammetry: a practical guide to facial image acquisition. Head and Face Medicine 20106 18. (https://doi.org/10.1186/1746160X-6-18)

9 Guo X, Meng T, Huang J, Wang X, Lian W, Deng K, Gao L, Wang Z, Xing B \& Long X. 3D facial analysis in acromegaly: gender-specific features and clinical correlations. Frontiers in Endocrinology 20189 722. (https://doi.org/10.3389/fendo.2018.00722)

10 Melmed S, Casanueva FF, Klibanski A, Bronstein MD, Chanson P, Lamberts SW, Strasburger CJ, Wass JA \& Giustina A. A consensus on the diagnosis and treatment of acromegaly complications. Pituitary 201316 294-302. (https://doi.org/10.1007/s11102-012-0420-x)

11 Melmed S, Bronstein MD, Chanson P, Klibanski A, Casanueva FF, Wass JAH, Strasburger CJ, Luger A, Clemmons DR \& Giustina A. A consensus statement on acromegaly therapeutic outcomes. Nature Reviews: Endocrinology 201814 552-561. (https://doi.org/10.1038/ s41574-018-0058-5)

12 Zhang Y, Guo X, Pei L, Zhang Z, Tan G \& Xing B. High levels of IGF-1 predict difficult intubation of patients with acromegaly. Endocrine 201757 326-334. (https://doi.org/10.1007/s12020-017-1338-x)

13 Farkas LG. Anthropometry of the Head and Face, 2nd ed. Raven Press, 1994.

14 Dostálová S, Šonka K, Šmahel Z, Weiss Vr \& Marek J. Cephalometric assessment of cranial abnormalities in patients with acromegaly. Journal of Cranio-Maxillofacial Surgery 200331 80-87. (https://doi. org/10.1016/S1010-5182(02)00182-8)

15 Kosilek RP, Frohner R, Wurtz RP, Berr CM, Schopohl J, Reincke M $\&$ Schneider HJ. Diagnostic use of facial image analysis software in endocrine and genetic disorders: review, current results and future perspectives. European Journal of Endocrinology 2015173 M39-M44. (https://doi.org/10.1530/EJE-15-0429)

16 Plooij JM, Swennen GR, Rangel FA, Maal TJ, Schutyser FA, Bronkhorst EM, Kuijpers-Jagtman AM \& Berge SJ. Evaluation of reproducibility and reliability of $3 \mathrm{D}$ soft tissue analysis using 3D stereophotogrammetry. International Journal of Oral and Maxillofacial Surgery 200938 267-273. (https://doi.org/10.1016/j. ijom.2008.12.009) 
17 Chen W, Qian W, Wu G, Chen W, Xian B, Chen X, Cao Y, Green CD, Zhao F, Tang $\mathrm{K}$ et al. Three-dimensional human facial morphologies as robust aging markers. Cell Research 201525 574-587. (https://doi. org/10.1038/cr.2015.36)

18 Wagenmakers MAEM, Roerink SHPP, Maal TJJ, Pelleboer RH, Smit JWA, Hermus ARMM, Berge SJ, Netea-Maier RT \& Xi T. Threedimensional facial analysis in acromegaly: a novel tool to quantify craniofacial characteristics after long-term remission. Pituitary 2015 18 126-134. (https://doi.org/10.1007/s11102-014-0565-x)

19 Hoevenaren IA, Wagenmakers MA, Roerink SH, Netea-Maier RT, Ulrich DJ \& Maal TJ. Three-dimensional soft tissue analysis of the hand: a novel method to investigate effects of acromegaly. European Journal of Plastic Surgery 201639 429-434. (https://doi.org/10.1007/ s00238-016-1217-3)

20 Shin HJ, Song WC, Lee SH, Ha HJ \& Koh KS. Consistency of the lateral canthus as an anatomic landmark and its clinical implications. Clinical Anatomy 201932 630-634. (https://doi.org/10.1002/ca.23360)

21 Chin OY \& Sykes JM. Optimizing the chin and jawline appearance: does surgery or injection make sense? Facial Plastic Surgery 201935 164-171. (https://doi.org/10.1055/s-0039-1683962)

22 Nguyen J \& Duong H. Anatomy, Head and Neck, Face. 2020 Jul 27. In: StatPearls [Internet]. Treasure Island (FL): StatPearls Publishing.

23 Fujio S, Arimura H, Hirano H, Habu M, Bohara M, Moinuddin FM, Kinoshita Y \& Arita K. Changes in quality of life in patients with acromegaly after surgical remission - a prospective study using SF-36 questionnaire. Endocrine Journal 201764 27-38. (https://doi. org/10.1507/endocri.EJ16-0182)

24 Yoshida K, Fukuoka H, Matsumoto R, Bando H, Suda K, Nishizawa H, Iguchi G, Ogawa W, Webb SM \& Takahashi Y. The quality of life in acromegalic patients with biochemical remission by surgery alone is superior to that in those with pharmaceutical therapy without radiotherapy, using the newly developed Japanese version of the AcroQoL. Pituitary 201518 876-883. (https://doi.org/10.1007/ s11102-015-0665-2)
25 Sardella C, Lombardi M, Rossi G, Cosci C, Brogioni S, Scattina I, Webb SM, Gasperi M, Martino E \& Bogazzi F. Short- and long-term changes of quality of life in patients with acromegaly: results from a prospective study. Journal of Endocrinological Investigation 201033 20-25. (https://doi.org/10.1007/BF03346555)

26 Han K, Park M, Choi T, Choi J, Kim J, Son D \& Jeong W. Septal integration graft, a modified direct type of septal extension graft for the treatment of unilateral cleft lip nose deformity: an anthropometric analysis. Annals of Plastic Surgery 202084 47-52. (https://doi.org/10.1097/SAP.0000000000002118)

27 Wang Y, Guo S, Sun Q, Jin SF, Zhang X, Xiao M, Wang CC, Sun X, Lv MZ \& Li KZ. Anthropometric labial analysis of Han Chinese young adults. Skin Research and Technology 201925 499-503. (https:// doi.org/10.1111/srt.12678)

28 Colao A, Ferone D, Marzullo P \& Lombardi G. Systemic complications of acromegaly: epidemiology, pathogenesis, and management. Endocrine Reviews 200425 102-152. (https://doi. org/10.1210/er.2002-0022)

29 Xie T, Ding H, Xia M, Zhang X, Sun W, Liu T, Gu Y, Sun C \& Hu F. Dynamic changes in the distribution of facial and abdominal adipose tissue correlated with surgical treatment in acromegaly. Endocrine 201862 552-559. (https://doi.org/10.1007/s12020-0181742-x)

30 Choi SH, Fan D, Hwang MS, Lee HK \& Hwang CJ. Effect of growth hormone treatment on craniofacial growth in children: idiopathic short stature versus growth hormone deficiency. Journal of the Formosan Medical Association 2017116 313-321. (https://doi. org/10.1016/j.jfma.2016.05.011)

31 Danna NR, Beutel BG, Ramme AJ, Kirsch T, Kennedy OD \& Strauss E. The effect of growth hormone on chondral defect repair. Cartilage 20189 63-70. (https://doi.org/10.1177/1947603516678973)

32 Maffezzoni F \& Formenti AM. Acromegaly and bone. Minerva Endocrinology 201843 168-182. (https://doi.org/10.23736/S03911977.17.02733-X)

Received 23 August 2020

Revised version received 1 October 2020

Accepted 27 October 2020 